\title{
"Diminishing Returns" in the Scaling between Leaf Area and Twig Size in Three Forest Communities Along an Elevation Gradient of Wuyi Mountain, China
}

\author{
Guojie Zhu ${ }^{1,2}$, Karl Joseph Niklas ${ }^{3}$, Man Li ${ }^{1,2}$, Jun Sun ${ }^{1,2}$, Min Lyu ${ }^{1,2}$, Xiaoping Chen ${ }^{1,2}$, \\ Mantang Wang ${ }^{4}$, Quanlin Zhong ${ }^{1,2}$ and Dongliang Cheng ${ }^{1,2, *}$ \\ 1 Fujian Provincial Key Laboratory of Plant Ecophysiology, Fujian Normal University, Fuzhou 350007, China; \\ juliazgj@163.com (G.Z.); Limn12@163.com (M.L.); sunjunfjnu@aliyun.com (J.S.); almg168@126.com (M.L.); \\ cc_xiaoping@163.com (X.C.); qlzhong@126.com (Q.Z.) \\ 2 Key Laboratory of Humid Subtropical Eco-Geographical Process, Ministry of Education, \\ Fuzhou 350007, China \\ 3 Plant Biology Section, School of Integrative Plant Science, Cornell University, Ithaca, NY 14853, USA; \\ kjn2@cornell.edu \\ 4 School of City and Civil Engineering, Zaozhuang University, Zaozhuang 277160, China; \\ sailorwmt@gmail.com \\ * Correspondence: chengd102@aliyun.com; Tel./Fax: +86-591-834-65397
}

Received: 7 October 2019; Accepted: 10 December 2019; Published: 12 December 2019

\begin{abstract}
Background and aims: The "diminishing returns" hypothesis postulates that the scaling exponent governing the lamina area versus lamina mass scaling relationships has, on average, a numerical value less than one. Theoretically, a similar scaling relationship may exist at the twig level. However, this possibility has not been explored empirically. Methods: We tested both hypotheses by measuring the lamina area and mass, petiole mass of individual leaves, and the total foliage area and stem mass of individual current-year shoots (twigs) of 64 woody species growing in three characteristic forest community types: (1) Evergreen broad-leaved, (2) mixed coniferous and broad-leaved, and (3) deciduous. Key results: The results demonstrate that lamina area vs. mass and lamina area vs. petiole mass differ significantly among the three forest types at both the individual leaf and twig levels. Nevertheless, the scaling exponents of lamina area vs. mass were $<1.0$ in each of the three community types, as were the corresponding exponents for lamina area vs. petiole mass, both within and across the three community types. Similar trends were observed at the individual twig level. The numerical values of the scaling exponent for lamina area vs. petiole mass and total foliage area vs. stem mass per twig decreased with increased elevation. Conclusions: These data support the "diminishing returns" hypothesis at both the individual leaf level and at the individual twig level, phenomena that can inform future inquiries into the mechanistic basis of biomass allocation patterns to physiological (leaf) and mechanical (stem) plant organs.
\end{abstract}

Keywords: diminishing returns; leaf traits; plant allometry; scaling exponents; twig biomass allocation; Wuyi Mountain

\section{Introduction}

Leaf area varies by almost six orders of magnitude across species, ranging from less than $1.0 \mathrm{~mm}^{2}$ to more than $1.0 \mathrm{~m}^{2}$ [1]. As the primary light-harvesting organ for the majority of species, it is important to understand, both empirically and theoretically, how variation in leaf size (measured as area or mass) affects the capacity to capture solar energy and how this in turn affects ecosystem 
functions [2]. One approach is to analyze the size-dependent (scaling) relationships between leaf lamina area $(A)$ with respect to leaf mass and the mass $(M)$ of supporting structures, such as the petiole and stem, to determine whether they conform to the general scaling equation $A=\beta M^{\alpha}$, where $\beta$ is the normalization constant and $\alpha$ is the scaling exponent [3-5].

In this context, the "diminishing returns" hypothesis predicts that, at the individual leaf level, the interspecific scaling exponent governing the relationship between lamina area $\left(a_{1}\right)$ and lamina mass $\left(m_{1}\right)$, on average, will be less than unity (i.e., $\left.\alpha<1.0\right)$, such that incremental gains in lamina mass fail to produce proportional increases in lamina area [5]. If true, specific leaf area (SLA $\left.=a_{1} / \mathrm{mL}\right)$, which is a key index of photosynthetic efficiency [6,7], is predicted to decrease with increasing lamina mass across species. Furthermore, it is reasonable to suppose that a larger lamina area or mass would be associated with a more massive petiole, as reported by some early empirical work [8]. For example, using data collected from 44 species, Niinemets et al. [9] found that larger leaves tend to have disproportionately more massive petioles compared with smaller leaves. Pickup et al. [10] reached a similar conclusion. Taken together, the "diminishing returns" hypothesis and empirical data support the notion that increases in lamina area will fail to keep pace with increasing lamina and petiole mass $\left(m_{\mathrm{p}}\right)$ at the individual leaf level.

Lamina area and lamina mass are crucial leaf traits underpinning the metabolic performance of plants [11]. The "diminishing returns" economic principle provides one explanation for why the scaling of total plant growth as a function of total mass is governed by a scaling exponent with a value significantly less than one [12]. Although the "diminishing returns" hypothesis has been tested at the individual leaf level within and among species [5,13], it remains unclear whether this hypothesis holds for plants growing along major environmental gradients or different community types. For example, the scaling exponent of $a_{1}$ vs. $m_{1}$ can shift from $<1.0$ to $>1.0$ with increasing elevation, as shown by Pan et al. [14], whereas the corresponding scaling exponent for bamboos is $<1.0$ and more or less constant along an elevation gradient, as reported by Sun et al. [11]. Evidently, more comprehensive field data are needed to assess the generalizable validity of the "diminishing returns" hypothesis.

Another mostly untested aspect of this hypothesis is whether it holds true at the individual twig level, i.e., does total foliage area per twig scale at $<1.0$ with respect to total lamina and petiole mass $\left(M_{\mathrm{L}}\right.$ and $M_{\mathrm{P}}$, respectively)? In this regard, Niklas et al. [5] reported that total foliage area $\left(A_{\mathrm{L}}\right)$ per twig is proportional to both the leaf number per twig $\left(N_{\mathrm{L}}\right)$ and mean lamina area of individual leaves (i.e., $A_{\mathrm{L}} N_{\mathrm{L}} \times a_{1}$ ), and that $M_{\mathrm{L}}$ is also proportional to $N_{\mathrm{L}}$ and the mean lamina mass of individual leaves (i.e., $M_{\mathrm{L}} N_{\mathrm{L}} \times m_{1}$ ). If individual lamina area scales disproportionately (allometrically) with individual lamina mass (on average) as proposed by the "diminishing returns" hypothesis (i.e., $a_{1}$ $\left.m_{1}^{\alpha<1.0}\right)$, it is not unreasonable to speculate that total foliage area the twig level could be recast as $A_{\mathrm{L}}$ $N_{\mathrm{L}} \times m_{1}{ }^{\alpha<1.0} M_{\mathrm{L}}{ }^{\alpha<1.0}$. Similar reasoning leads to the conclusion that a negative scaling relationship exists between $A_{\mathrm{L}}$ and total petiole mass $\left(M_{\mathrm{P}}\right)$. Yet, to the best of our knowledge, there has been no systematic, extensive testing of the "diminishing returns" hypothesis conducted simultaneously at the individual leaf level and the individual twig level for different plant community types along an elevation gradient.

In order to fill this gap in our knowledge, we report on the lamina size (i.e., measured as lamina surface area and mass), petiole mass, and stem mass from the current-year shoots (i.e., twigs) of 64 woody plant species collected from three different types of forests (i.e., evergreen, mixed coniferous and broad-leaved, and deciduous) along an elevation gradient in China. Several key environmental conditions (i.e., light intensity, temperature, and nutrient availabilities) were also measured and recorded. The data were used to (1) test whether the "diminishing returns" hypothesis holds at both the individual leaf and twig levels, and (2) determine the scaling relationship between lamina area and total supporting mass (the sun of petiole and stem mass) at the twig level. 


\section{Materials and Methods}

\subsection{Site Description}

The study site is located in the National Natural Reserve of the Wuyi Mountains, southeastern China $\left(27^{\circ} 48.11^{\prime}-28^{\circ} 00.35^{\prime} \mathrm{N}, 117^{\circ} 39.30^{\prime}-117^{\circ} 55.47^{\prime} \mathrm{E}\right)$. The reserve has a typical subtropical monsoon climate, featuring abundant precipitation and abundant solar radiation. Mean annual precipitation is $2583 \mathrm{~mm}$, with a mean annual temperature of $14.2{ }^{\circ} \mathrm{C}$ and evaporation of $778 \mathrm{~mm}$, and $72-92 \%$ relative humidity (yearly average). The Wuyi Mountains are characterized by vertical vegetation zonation, going from evergreen forest at low elevation to mountainous steppe at high elevation. The area belongs to the mid-subtropical monsoon climate, with an annual average temperature of $13.2 \sim 14.8^{\circ} \mathrm{C}$, an extreme minimum temperature of $-14.2{ }^{\circ} \mathrm{C}$, an extreme maximum temperature of $36.3{ }^{\circ} \mathrm{C}$, and an increase in altitude. The annual, monthly, and seasonal average temperatures decrease with the annual average. The vertical decline rate of temperature is $0.44{ }^{\circ} \mathrm{C} / 100 \mathrm{~m}$, that is, for every $100 \mathrm{~m}$ rise, the annual average temperature drops by $0.44{ }^{\circ} \mathrm{C}$. The average annual precipitation is $2583 \mathrm{~mm}$, and the period from April to June is the precipitation concentration period in the area. The annual evaporation is $778 \mathrm{~mm}$, and the annual average relative humidity is $72-92 \%$. The annual sunshine hours are 774-1144 h, and the annual average frost-free period is 231 days [15]. The major soil types are classified as mountain yellow-red soil (400-600 m a.s.1.), mountain yellow soil (600-1300 m a.s.1.), mountain dark yellow-brown soil (1300-1900 m a.s.1.), and mountain meadow soil (above $1900 \mathrm{~m}$ a.s.1.) [16].

\subsection{Leaf and Twig Sampling}

Based on the distribution pattern of forest ecosystems at Wuyi Mountain, three types of forest discernable along the elevation gradient were selected: Evergreen broad-leaved forest (EF; $1319 \mathrm{~m}$ a.s.1.), a mixed forest (MF; $1697 \mathrm{~m}$ a.s.1.), and a deciduous forest (DF; $1818 \mathrm{~m}$ a.s.1.). A total of 32, 20, and 23 species (including overlapping species) were respectively sampled in EF, MF, and DF (Table 1). The dominant species in the EF were Rhododendron simiarum Hance, Schima superba, Gardner \& Champ., Cyclobalanopsis glauca (Thunb.) Oerst., Rhododendron ovatum (Lindl.) Planch. ex Maxim., and Symplocos sumuntia Buch.-Ham. ex D. Don; the MF was dominated by Symplocos sumuntia, Cyclobalanopsis multiervis W. C. Cheng et T. Hong, Tsuga chinensis (Franch.) Pritzel ex Diels., Taxu schinensis (Rehder \& E.H.Wilson) Rehder, Acer elegantulum W.P.Fang \& P.L.Chiu, and Illicium minwanense B. N. Chang et S. D. Zhang; and the DF was dominated by Clethra barbinervis Siebold \& Zucc., Photinia beauverdiana C. K. Schneider, Acer nikoense Miq., and Fraxinus chinensis Roxb. [17]. The stand densities were 3033 trees $/ \mathrm{hm}^{2}$, 1133 trees $/ \mathrm{hm}^{2}$, and 2725 trees/ $\mathrm{hm}^{2}$ for EF, MF, and DF, respectively, with corresponding mean plant heights of $7.87 \mathrm{~m}, 10.56 \mathrm{~m}$, and $6.94 \mathrm{~m}$. Three $20 \mathrm{~m} \times 20 \mathrm{~m}$ plots were established in each forest type, with at least a $20 \mathrm{~m}$ spacing between plots. In each plot, all healthy woody plants with a diameter at breast height $(\mathrm{DBH})>5 \mathrm{~cm}$ were marked and their species, $\mathrm{DBH}$, and height recorded.

Table 1. Summary of species taxa of different forest communities in Wuyi Mountain.

\begin{tabular}{ccccccccc}
\hline Forest Type & PFT $_{\mathbf{S}}$ & Family & Genus & Species & Lifeform & Family & Genus & Species \\
\hline \multirow{2}{*}{ EF } & arbor & 9 & 15 & 18 & evergreen & 8 & 13 & 22 \\
& shrub & 10 & 11 & 14 & deciduous & 9 & 10 & 10 \\
\hline \multirow{2}{*}{ MF } & arbor & 9 & 10 & 12 & evergreen & 8 & 10 & 13 \\
& shrub & 4 & 5 & 8 & deciduous & 5 & 5 & 7 \\
\hline \multirow{2}{*}{ DF } & arbor & 8 & 8 & 9 & evergreen & 5 & 5 & 6 \\
& shrub & 12 & 13 & 14 & deciduous & 14 & 16 & 17 \\
\hline
\end{tabular}

Note: EF, evergreen forest; MF, mixed forest; DF, deciduous forest; $\mathrm{PFT}_{\mathrm{S}}$, a collection of species with similar structures or functions. 
Three to five representative individuals of each plant species were selected, from which five current-year twigs of medium size with mature leaves (but lacking reproductive organs) were randomly selected at the periphery and two sides of each plant's crown. Twigs were removed and placed into sealable plastic bags with their ID-code and brought to the laboratory to separate laminas, petioles, and stems. The length and diameter of each stem were measured with a ruler and a vernier caliper, respectively, and the total number of leaves counted. All individual leaves on twigs were digitally scanned using an Epson scanner (Epson V39, Epson, Japan). After separating the organ components, the fresh lamina mass and area, petiole mass, stem mass, and quantitative characteristics of the twig parts and accessories were measured. All leaves on a given twig were removed to measure total foliage area and mass at the twig level. Immediately afterwards, the laminas, petioles, and stems were oven-dried at $75^{\circ} \mathrm{C}$ to constant weight to determine their respective dry mass. Each scanned lamina was analyzed using ImageJv1.2 software (National Institute of Health, Bethesda, MD, USA), and its lamina area $\left(a_{1}\right)$ was recorded.

\subsection{Data Analysis}

The scaling relationships among lamina area and mass, petiole mass, stem mass, and total supporting mass ( $M_{\mathrm{STM}}$; the sum of petiole and stem mass) at the individual leaf and twig level were analyzed using the equation $Y_{1}=\beta Y_{2}{ }^{\alpha}$, where $Y_{1}$ and $Y_{2}$ are the interdependent variables of interest, $\alpha$ is the scaling exponent, and $\beta$ is the normalization constant. All equations were $\log _{10}$-transformed to yield $\log Y_{1}=\log \beta+\alpha \log Y_{2}$. Scaling relationships were quantified using the "smatr" package v 3.4-3 [18] in the R v3.2.3 software platform ( $R$ Development Core Team 2012; R Foundation for Statistical Computing, Vienna, Austria). The significance level used for testing slope heterogeneity was set a priori at $p \leq 0.05$ (i.e., slope heterogeneity was rejected for $p$-values $>0.05$ ).

\section{Results}

\subsection{Variation in Lamina Size, Petiole and Stem Mass at the Leaf and Twig Levels}

Across the three forest types, at the individual leaf level, mean values of petiole mass $\left(m_{\mathrm{p}}\right)$, lamina mass $\left(m_{1}\right)$, and lamina area $\left(a_{1}\right)$ individual leaf were $0.010 \mathrm{~g}, 0.168 \mathrm{~g}$, and $2228 \mathrm{~mm}^{2}$, respectively. The $m_{\mathrm{p}}$ differed significantly among the three forest communities, but not $a_{1}$, and individual leaf mass $\left(m_{\mathrm{L}}\right)$ decreased significantly as elevation increased (Table 2$)$.

At the twig level, the mean values of $M_{\mathrm{L}}$, petiole mass $\left(M_{\mathrm{P}}\right), M_{\mathrm{S}}, A_{\mathrm{L}}$, and $M_{\mathrm{STM}}$ were, respectively, $0.824 \mathrm{~g}, 0.052 \mathrm{~g}, 0.107 \mathrm{~g}, 10994 \mathrm{~mm}^{2}$, and $0.154 \mathrm{~g}$ across the three forest types (Table 3). The $M_{L}$ of the three forest types declined with elevation, being significantly lowest in DF, while the $A_{\mathrm{L}}$ in the EF and DF significantly exceeded that of the MF (Table 2). 
Table 2. Leaf-level and twig-level biomass allocation (mean \pm standard error (SE)) in different forest type son Wuyi Mountain (China).

\begin{tabular}{|c|c|c|c|c|c|c|c|c|c|c|}
\hline \multirow{2}{*}{ Type } & \multicolumn{5}{|c|}{ Leaf-level } & \multicolumn{5}{|c|}{ Twig-Level } \\
\hline & $n$ & $m_{\mathrm{p}}(\mathrm{g})$ & $m_{1}(\mathrm{~g})$ & $a_{1}(\mathrm{~mm}$ & $m_{\mathrm{L}}(\mathrm{g})$ & $M_{\mathrm{L}}(\mathrm{g})$ & $M_{\mathrm{P}}(\mathrm{g})$ & $M_{\mathrm{S}}(\mathrm{g})$ & $A_{\mathrm{L}}\left(\mathrm{mm}^{2}\right)$ & $M_{\mathrm{STM}}(\mathrm{g})$ \\
\hline $\mathrm{EF}$ & 335 & $0.011 \pm 0.52 b$ & $0.2 \pm 8.19 a$ & $2286 \pm 66.83 a$ & $0.21 \pm 8.66 a$ & $0.91 \pm 34.59 \mathrm{a}$ & $0.051 \pm 2.71 b$ & $0.111 \pm 4.51 \mathrm{a}$ & $10983 \pm 349.75 a$ & $0.162 \pm 6.17 a$ \\
\hline MF & 205 & $0.014 \pm 0.93 a$ & $0.173 \pm 11.77 \mathrm{~b}$ & $2135 \pm 115.14 a$ & $0.184 \pm 12.45 b$ & $0.808 \pm 69.04 a$ & $0.063 \pm 5.54 \mathrm{a}$ & $0.088 \pm 7.85 b$ & $9509 \pm 677.66 b$ & $0.137 \pm 12.07 \mathrm{~b}$ \\
\hline DF & 375 & $0.009 \pm 0.42 c$ & $0.138 \pm 5.61 c$ & $2228 \pm 72.10 a$ & $0.145 \pm 5.94 c$ & $0.755 \pm 36.67 b$ & $0.048 \pm 2.86 b$ & $0.114 \pm 5.57 \mathrm{a}$ & $11816 \pm 413.51 a$ & $0.156 \pm 7.74 a$ \\
\hline All & 915 & $0.010 \pm 0.33$ & $0.168 \pm 4.69$ & $2228 \pm 46.21$ & $0.178 \pm 4.96$ & $0.824 \pm 25.08$ & $0.052 \pm 1.92$ & $0.107 \pm 3.33$ & $10994 \pm 262.39$ & $0.154 \pm 4.75$ \\
\hline
\end{tabular}

Note: Different letters $(\mathrm{a}, \mathrm{b}$, and $\mathrm{c})$ within a column indicate significant differences among forest types at the $p<0.05$ level.

Table 3. Relationships between biomass allocation to different leaf-level components in three forest communities on Wuyi Mountain (China).

\begin{tabular}{ccccccc}
\hline $\log \mathbf{y}$ vs. $\log \mathbf{x}$ & Forests & $n$ & $\alpha(\mathbf{9 5} \% \mathbf{C I s})$ & $\log \beta(\mathbf{9 5} \% \mathbf{C I s})$ & $r^{2}$ & $p$ \\
\hline \multirow{4}{*}{$a_{1}$ vs. $m_{1}$} & EF & 335 & $0.79(0.74,0.84)$ & $1.57(1.45,1.68)$ & 0.62 & $<0.001$ \\
& MF & 205 & $1.00(0.96,1.03)$ & $1.13(1.06,1.20)$ & 0.94 & $<0.001$ \\
& DF & 375 & $0.92(0.87,0.96)$ & $1.40(1.31,1.49)$ & 0.77 & $<0.001$ \\
& All & 915 & $0.94(0.92,0.97)$ & $1.28(1.23,1.34)$ & 0.83 & $<0.001$ \\
\hline \multirow{4}{*}{$a_{1}$ vs. $m_{\mathrm{p}}$} & EF & 335 & $0.68(0.63,0.73)$ & $2.70(2.65,2.75)$ & 0.52 & $<0.001$ \\
& MF & 160 & $0.65(0.60,0.71)$ & $2.72(2.66,2.78)$ & 0.67 & $<0.001$ \\
& DF & 330 & $0.74(0.68,0.80)$ & $2.72(2.67,2.77)$ & 0.43 & $<0.001$ \\
& All & 825 & $0.68(0.65,0.72)$ & $2.72(2.69,2.75)$ & 0.51 & $<0.001$ \\
\hline & EF & 335 & $0.86(0.82,0.90)$ & $1.44(1.40,1.48)$ & 0.81 & $<0.001$ \\
$m_{1}$ vs. $m_{\mathrm{p}}$ & MF & 160 & $0.82(0.77,0.87)$ & $1.42(1.37,1.48)$ & 0.85 & $<0.001$ \\
& DF & 330 & $0.89(0.83,0.94)$ & $1.36(1.31,1.41)$ & 0.67 & $<0.001$ \\
& All & 825 & $0.86(0.83,0.89)$ & $1.40(1.38,1.43)$ & 0.77 & $<0.001$ \\
\hline \multirow{5}{*}{$a_{1}$ vs. $m_{\text {L }}$} & EF & 335 & $0.79(0.74,0.84)$ & $1.55(1.43,1.67)$ & 0.62 & $<0.001$ \\
& MF & 160 & $0.99(0.96,1.02)$ & $1.12(1.05,1.19)$ & 0.94 & $<0.001$ \\
& DF & 330 & $0.91(0.87,0.96)$ & $1.39(1.30,1.48)$ & 0.77 & $<0.001$ \\
& All & 825 & $0.94(0.91,0.96)$ & $1.27(1.22,1.33)$ & 0.83 & $<0.001$ \\
\hline
\end{tabular}

Note: $a_{1}$, individual lamina area; $m_{1}$, individual lamina mass; $m_{\mathrm{p}}$, individual petiole mass; $m_{\mathrm{L}}$, individual leaf mass; $95 \%$ CIs, $95 \%$ confidence intervals. 


\subsection{Scaling Relationships at the Leaf Level among Lamina Area and Mass, and Petiole Mass}

Statistically robust correlations of $a_{1}$ with respect to other twig traits at the individual leaf level were detected in each of the three forest types (Tables 1 and 2). Specifically, the scaling exponents of $a_{1}$ vs. $m_{1}$ were significantly $<1.0$ in the EF and DF, being respectively 0.79 (95\% CIs $=0.74,0.84, n=335$, $\left.r^{2}=0.62\right)$ and $0.92\left(95 \%\right.$ CIs $\left.=0.87,0.96, n=375, r^{2}=0.77\right)$ (Table 3; Figure 1A). By contrast, $a_{1}$ scaled is ometrically with $m_{1}$ in the MF (i.e., $\alpha=1.00,95 \%$ CIs $=0.96,1.03, n=205, r^{2}=0.94$ ) (Table 3; Figure 1A). Across all three forest types, $a_{1}$ scaled all ometrically and not is ometrically with respect to $m_{1}$ (Table 3 ; Figure 1A).
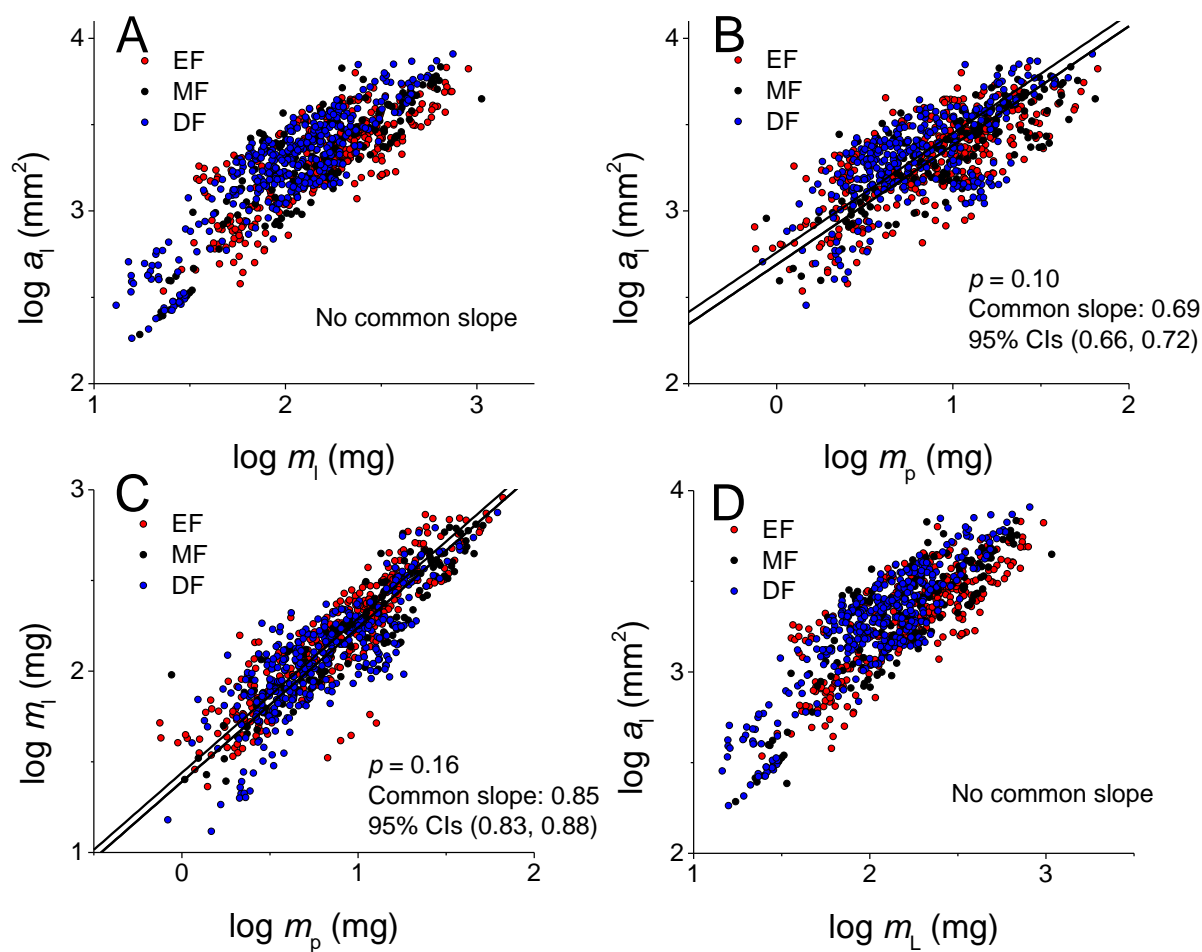

Figure 1. (A) relationships between $\mathrm{a}_{1}$ and $\mathrm{m}_{1}$ in three forest community types at Wuyi Mountain, China; (B) relationships between $\mathrm{a}_{1}$ and $\mathrm{m}_{\mathrm{p}}$ in three forest community types at Wuyi Mountain, China; (C) relationships between $\mathrm{m}_{1}$ and $\mathrm{m}_{\mathrm{p}}$; (D) relationships between $\mathrm{a}_{1}$ and $\mathrm{m}_{\mathrm{L}}$ in three forest community types at Wuyi Mountain, China. EF, evergreen forest; MF, mixed forest; DF, deciduous forest. $a_{1}$, individual lamina area; $\mathrm{m}_{1}$, individual lamina mass; $\mathrm{m}_{\mathrm{p}}$, individual petiole mass; $\mathrm{m}_{\mathrm{L}}$, individual leaf mass.

Lamina area scaled significantly with respect to petiole mass within and across the three forest types (Tables 2 and 3). The scaling exponents of $a_{1}$ vs. $m_{\mathrm{p}}$ did not differ significantly among the three forest types ( $p=0.1)$, having a common slope of $0.69(95 \% \mathrm{CIs}=0.66,0.72)$. However, the normalization constants of $a_{1}$ vs. $m_{\mathrm{p}}$ increased significantly with elevation (Table 3; Figure 1B). Similarly, $m_{1}$ increased significantly with $m_{\mathrm{p}}$ in each of the three forest community types (Tables 2 and 3), for which the scaling exponents were all significantly $<1.0$, having a common slope of 0.85 (95\% CIs = 0.83, 0.88; Figure 1C), although their scaling constants of $m_{1}$ vs. $m_{\mathrm{p}}$ declined with altitude (Table 2 ). The scaling exponents of $a_{1}$ vs. $m_{\mathrm{L}}$ differed among the three forest types. However, they were all significantly $<1.0$ (Table 3; Figure 1D). Furthermore, across the three forest types, $a_{1}$ scaled significantly with an exponent $<1.0$ with respect to $m_{\mathrm{L}}\left(95 \%\right.$ CIs $\left.=0.91,0.96, n=825, r^{2}=0.83\right)$ (Table 2; Figure 1D). 


\subsection{Scaling Relationships at the Twig Level among Lamina Areaand Petiole and Stem Mass}

Statistically robust regressions of $A_{\mathrm{L}}$ with respect to other twigs traits at the twig level were detected in each forest type (Table 4). Specifically, the scaling exponents for $A_{\mathrm{L}} \mathrm{vs} . \mathrm{M}_{\mathrm{L}}$ in EF, MF, and DF were $0.90\left(95 \%\right.$ CIs $\left.=0.84,0.96, n=335, r^{2}=0.60\right), 0.95\left(95 \%\right.$ CIs $\left.=0.90,0.99, n=160, r^{2}=0.88\right)$, and $0.90\left(95 \% \mathrm{CIs}=0.86,0.94, n=330, r^{2}=0.78\right)$, respectively; each was significantly $<1.0$, with a common slope of $0.92(95 \%$ CIs $=0.89,0.95)$ (Table 4; Figure 2A).

Table 4. Between biomass allocation to different twig-level components in three forest communities on Wuyi Mountain (China).

\begin{tabular}{|c|c|c|c|c|c|c|}
\hline $\log y$ vs. $\log x$ & Forests & $n$ & $\alpha(95 \% \mathrm{CIs})$ & $\log \beta$ (95\%CIs) & $r^{2}$ & $p$ \\
\hline \multirow{4}{*}{$A_{\mathrm{L}}$ vs. $M_{\mathrm{L}}$} & $\mathrm{EF}$ & 335 & $0.90(0.84,0.96)$ & $1.40(1.22,1.57)$ & 0.60 & $<0.001$ \\
\hline & MF & 160 & $0.95(0.90,0.99)$ & $1.27(1.15,1.39)$ & 0.88 & $<0.001$ \\
\hline & $\mathrm{DF}$ & 330 & $0.90(0.86,0.94)$ & $1.52(1.40,1.64)$ & 0.78 & $<0.001$ \\
\hline & All & 825 & $0.92(0.90,0.95)$ & $1.37(1.29,1.45)$ & 0.76 & $<0.001$ \\
\hline \multirow{4}{*}{$A_{\mathrm{L}}$ vs. $M_{\mathrm{P}}$} & $\mathrm{EF}$ & 335 & $0.71(0.66,0.76)$ & $2.87(2.79,2.95)$ & 0.56 & $<0.001$ \\
\hline & MF & 160 & $0.72(0.66,0.78)$ & $2.83(2.73,2.92)$ & 0.73 & $<0.001$ \\
\hline & DF & 330 & $0.67(0.62,0.72)$ & $3.01(2.93,3.09)$ & 0.54 & $<0.001$ \\
\hline & All & 825 & $0.70(0.67,0.73)$ & $2.91(2.86,2.96)$ & 0.57 & $<0.001$ \\
\hline \multirow{4}{*}{$A_{\mathrm{L}}$ vs. $M_{\mathrm{S}}$} & $\mathrm{EF}$ & 335 & $0.85(0.78,0.92)$ & $2.32(2.18,2.47)$ & 0.33 & $<0.001$ \\
\hline & MF & 160 & $1.03(0.96,1.10)$ & $2.02(1.89,2.15)$ & 0.74 & $<0.001$ \\
\hline & DF & 330 & $0.71(0.66,0.76)$ & $2.67(2.57,2.76)$ & 0.53 & $<0.001$ \\
\hline & All & 825 & $0.85(0.81,0.89)$ & $2.35(2.28,2.42)$ & 0.54 & $<0.001$ \\
\hline \multirow{4}{*}{$A_{L}$ vs. $M_{S T M}$} & $\mathrm{EF}$ & 335 & $0.85(0.79,0.92)$ & $2.17(2.03,2.31)$ & 0.48 & $<0.001$ \\
\hline & MF & 160 & $0.93(0.88,0.98)$ & $2.03(1.94,2.13)$ & 0.86 & $<0.001$ \\
\hline & DF & 330 & $0.75(0.71,0.80)$ & $2.47(2.37,2.56)$ & 0.64 & $<0.001$ \\
\hline & All & 825 & $0.85(0.82,0.88)$ & $2.22(2.16,2.28)$ & 0.67 & $<0.001$ \\
\hline \multirow{4}{*}{$M_{\mathrm{P}}$ vs. $M_{\mathrm{S}}$} & $\mathrm{EF}$ & 335 & $1.19(1.10,1.30)$ & $-0.76(-0.95,-0.58)$ & 0.47 & $<0.001$ \\
\hline & MF & 160 & $1.06(0.97,1.16)$ & $-0.37(-0.56,-0.18)$ & 0.64 & $<0.001$ \\
\hline & $\mathrm{DF}$ & 330 & $0.88(0.81,0.94)$ & $-0.15(-0.27,-0.02)$ & 0.52 & $<0.001$ \\
\hline & All & 825 & $0.92(0.90,0.95)$ & $1.37(1.29,1.45)$ & 0.76 & $<0.001$ \\
\hline
\end{tabular}

Note: $A_{\mathrm{L}}$, total foliage area; $M_{\mathrm{L}}$, total foliage mass; $M_{\mathrm{P}}$, total petiole mass; $M_{\mathrm{S}}$, stem mass; $M_{S T M}$, summed petiole and stem mass; $95 \%$ CIs, $95 \%$ confidence intervals.

The scaling exponents for $A_{\mathrm{L}}$ vs. $M_{\mathrm{P}}$ in the $\mathrm{EF}$ and MF were, respectively, 0.71 (95\% CIs $=0.66$, $\left.0.76, n=335, r^{2}=0.56\right)$ and $0.72\left(95 \%\right.$ CIs $\left.=0.66,0.78, n=160, r^{2}=0.73\right)$, each being significantly $<1.0$ with a common slope of $0.70(95 \% \mathrm{CIs}=0.67,0.73)$ (Table 3; Figure 2B). Further, the scaling exponent in the DF was $0.67\left(95 \% \mathrm{CIs}=0.62,0.72, n=330, r^{2}=0.54\right)$ and also significantly $<1.0$ (Table 4; Figure 2B).

For $A_{\mathrm{L}}$ vs. $M_{\mathrm{S}}$, the scaling exponents in the EF and DF were, respectively, $0.85(95 \% \mathrm{CIs}=0.78$, $\left.0.92, n=335, r^{2}=0.33\right)$ and $0.71\left(95 \%\right.$ CIs $\left.=0.66,0.76, n=330, r^{2}=0.53\right)$ and significantly <1.0 (Table 4). In contrast, $A_{\mathrm{L}}$ in the MF scaled is ometrically with respect to $M_{\mathrm{S}}$, with an exponent of 1.03 (95\% CIs $=0.96,1.10, n=160, r^{2}=0.74$; Table 4). Further, across the three forest types, $A_{\mathrm{L}}$ scaled all ometrically with respect to $M_{\mathrm{S}}$, with each having exponents significantly $<1.0$ (Table 4; Figure 2C).

For $A_{\mathrm{L}}$ vs. $\mathrm{M}_{\mathrm{STM}}$, the EF, MF, and DF had scaling exponents of $0.85(95 \%$ CIs $=0.79,0.92, n=335$, $\left.r^{2}=0.48\right), 0.93\left(95 \%\right.$ CIs $\left.=0.88,0.98, n=160, r^{2}=0.86\right)$, and $0.75\left(95 \%\right.$ CIs $\left.=0.71,0.80, n=330, r^{2}=0.64\right)$; both were significantly $<1.0$ (Table 4), as in the case across the three forest types (Table 4; Figure 2D).

Finally, the scaling exponents of $M_{\mathrm{P}}$ vs. $M_{\mathrm{S}}$ decreased significantly with increasing elevation, going from $1.19\left(95 \% \mathrm{CIs}=1.10,1.30, n=335, r^{2}=0.47\right)$ in the $\mathrm{EF}$ to $0.88(95 \% \mathrm{CIs}=0.81,0.94, n=330$, $\left.r^{2}=0.52\right)$ in the DF (Table 4; Figure 2E). 

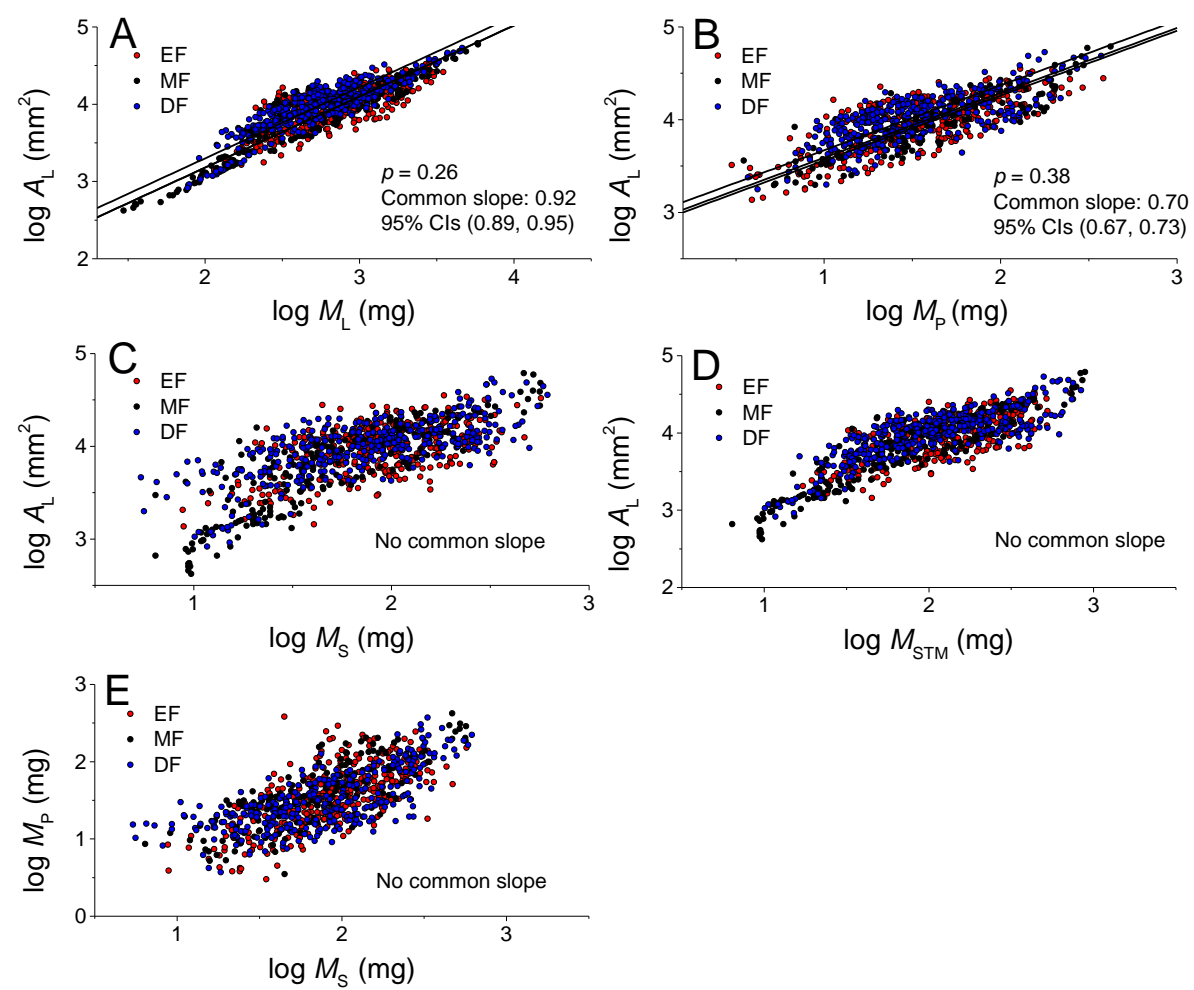

Figure 2. (A) relationship between $A_{\mathrm{L}}$ and $M_{\mathrm{L}}$ in three forest community types at Wuyi Mountain, China; (B) relationship between $A_{\mathrm{L}}$ and $M_{\mathrm{P}}$ in three forest community types at Wuyi Mountain, China; (C) relationship between $A_{\mathrm{L}}$ and $M_{\mathrm{S}}$ in three forest community types at Wuyi Mountain, China; (D) relationship between $A_{\mathrm{L}}$ and $M_{\mathrm{STM}}$ in three forest community types at Wuyi Mountain, China; E: relationship between $M_{\mathrm{P}}$ and $M_{\mathrm{S}}$ in three forest community types at Wuyi Mountain, China. EF, evergreen forest; $\mathrm{MF}$, mixed forest; $\mathrm{DF}$, deciduous forest. $A_{\mathrm{L}}$, total foliage area; $M_{\mathrm{L}}$, total foliage mass; $M_{\mathrm{P}}$, total petiole mass; $M_{\mathrm{S}}$, stem mass; $M_{S T M}$, summed petiole and stem mass.

\section{Discussion}

\subsection{Thelamina Area vs. Lamina Mass Scaling Relationship}

Our results indicate that the numerical value of the scaling exponent governing the relationships between lamina area $\left(a_{1}\right)$ and lamina mass $\left(m_{1}\right)$ is less than 1.0 along an elevational gradient in the evergreen and deciduous forests of Wuyi Mountain and across all three forest types at the individual leaf level. Therefore, the data support a key prediction of the "diminishing returns" hypothesis [5,19], i.e., increases in lamina area fail to keep pace with increases in lamina mass at the individual leaf level. We also found that the scaling exponent for $a_{1}$ versus $m_{1}$ is less than 1.0 in the highest elevation forest (the DF), a result inconsistent with Pan et al. [14], who report a scaling exponent $>1.0$ at a comparable elevation. One plausible explanation for this discrepancy is differences between the species composition and the precipitation and temperature associated with the two different environments, both of which can influence the scaling relationship between lamina area and lamina mass $[5,20,21]$.

Perhaps more importantly, our analyses demonstrate that the scaling exponent for whole lamina area versus total foliage mass is less than 1.0 at the level of current-year twigs, both within and across the three forest types (Table 4; Figure 2A). With increasing leaf vascular lignifications, the dry-weight investment on a per-leaf area basis should increase, yielding a lower SLA for large-sized leaves [6,7]. If this is a general phenomenon, it would imply that leaf area, as an investment trait for capturing more light, would gradually fail to keep pace with increasing leaf biomass. Indeed, some empirical results indicate that whole-plant leaf area scales as a 0.90 power law with respect to whole-plant leaf mass in a young Hinoki cypress forest [22]. Likewise, it is known that net primary production (NPP) in older 
forest stands declines [23]. It is possible that the diminishing returns hypothesis helps to explain why the efficiency of light harvesting decreases as total leaf biomass increases, such that NPP declines as forests age. Clearly, more data are needed to verify the link between diminishing returns and declining NPP in forest ecosystems.

\subsection{Scaling Relationships of Lamina Area and Petiole Mass}

Petiole investment has an important influence on biomass allocation at the twig level [9,24-26]. For example, previous studies have shown that petiole investment is size-dependent [9], varying from ca. 2 to $30 \%$, and by even more than $60 \%$ in the largest leaves $[8,9,25]$. However, the scaling relationships between lamina area and petiole mass have seldom been determined for woody plants at both the within-leaf and within-twig level.

Once again, our data are consistent with a size-dependent (scaling) relationship between lamina area and petiole mass predicted by the diminishing returns hypothesis, i.e., increases in lamina area $\left(a_{1}\right)$ fail to keep pace with increases in petiole biomass $\left(m_{\mathrm{p}}\right)$ at both the individual leaf and twig levels, both within and across different forest types (Tables 3 and 4; Figures 1 and 2). These results are interesting from a biomechanical as well as a metabolic perspective, because a petiole mechanically behaves as an elastic cantilevered beam that must support the static load of the leaf lamina [24]. The capacity of a cantilevered beam to static loads becomes less efficient as the beam becomes longer [27]. Therefore, with increasing lamina area, a disproportionately larger investment must be provided to provide mechanical support [20]. Similarly, fluid mechanics shows that the dynamic drag force induced by wind pressure is proportional to lamina area [24,27] and that this force is transmitted to the petiole $[20,24,27,28]$. Taken together, these two facts help to explain why petiole mass increases disproportionately with respect to lamina area and mass. Indeed, consistent with our results, prior studies have shown that the scaling exponent relating lamina area and petiole mass is significantly $<1.0$ in different subtropical forest types [26,29]. Our data similarly show that lamina area fails to keep pace with increases in total supporting biomass (i.e., the sum of stem and petiole mass) within and across the three forest communities examined in this study.

\subsection{Scaling Relationships of Petiole and Stem Biomass Along an Elevation Gradient}

Previous studies have generally neglected the effects of abiotic factors on structural biomass allocation patterns. In the present study, we examined the scaling relationship between total petiole mass and stem mass (i.e., $M_{\mathrm{P}}$ and $M_{\mathrm{S}}$ ) at the whole twig level across three forest communities. We have shown that this relationship shifts systematically, in that the numerical value of the scaling exponent decreases with increasing elevation (Table 4; Figure 2E), i.e., for any given petiole biomass, woody plants in the evergreen and mixed forests allocate more stem biomass than those in the deciduous forest.

A likely explanation for this result is the adaptations of deciduous versus non-deciduous species to changes in precipitation and temperature along an elevational gradient. Arguably, it is reasonable to speculate that the risk of hydraulic failure will increase (and access of soil nutrients will decrease) with increasing elevation [30,31]. A case in point is the deciduous forest, which is distributed at high elevations in our study region. Within this region, water, temperature, and other stress factors measurably increase. Species adapted to this ecosystem tend to have reduced leaf biomass and increased investments in supporting biomass, presumably to maintain a functioning nutrient and hydraulic transport system [32]. In addition, twigs also require additional investment in stem biomass to provide adequate support to cope with wind and snow mechanical loadings [24]. Otherwise, the high-altitude site is often windy in winters and suffers from winter snow cover. Windy environments necessitate a high investment in stems or petioles, as suggested by Niklas [24,28]. Yet, interpreting the relationship between leaf biomass and stem biomass at the twig level along an elevation gradient must be done cautiously. For example, Yang et al. [33] report that leaf biomass scales is ometrically with respect to stem biomass along an elevational gradient. In this particular case, the scaling relationship between lamina and petiole mass in tandem with the systematic shift in petiole versus stem mass can 
conceivably lead to variations in the investment of lamina area in different forest types, even with a constant biomass allocation between leaf and stem biomass.

\section{Conclusions}

We conclude that there is a diminishing return between increase biomass and leaf area as elevation increases. The predictions of the diminishing returns hypothesis appear to hold for twigs as well as leaves across diverse woody plants species. Furthermore, biomass investments in petiole and stem tissues vary with elevation in a manner that is consistent with the predictions of the diminishing returns hypothesis when juxtaposed with simple biomechanical considerations. These findings can serve to inform future inquiries into the mechanistic basis of twig biomass allocation patterns between metabolically active tissues and structurally supportive tissues, and future attempts to model twig ecophysiological traits.

We anticipate that biomass investment in supporting (petiole and stem) structures will be shown to be responsive to environmental gradients and as leaf area increases within and across different species. More comprehensive data sets, for many co-occurring species under a variety of environmental conditions, are still needed to assess the generality of the "diminishing returns" hypothesis in plant scaling theory.

Author Contributions: D.C. and M.L. conceived and designed the experiments. J.S., X.C., and M.L. (Man Li) performed the experiments. J.S., M.L. (Min Lyu), G.Z., D.C. and Q.Z. analyzed the data. G.Z., M.W., K.J.N. and D.C. wrote the manuscript. All authors contributed critically to the drafts and gave final approval for publication.

Funding: This work was supported by the National Natural Science Foundation of China (31722007), the National Key Research and Development Program of China (2017YFC0505400), and the Fujian Natural Science Funds for Distinguished Young Scholars (2018J07003).

Acknowledgments: The authors thank Y. R. Guo., L. Cheng., and R. B. Yuan. for their hospitality during the implementation of the study in the National Nature Reserve of Wuyi Mountain. The authors also appreciate the twig sampling collection assistance provided by Y. S. Chen.

Conflicts of Interest: The authors declare no conflict of interest.

\section{References}

1. Niklas, K.J.; Enquist, B.J. On the vegetative biomass partitioning of seed plant leaves, stems, and roots. Am. Nat. 2002, 59, 482-497. [CrossRef]

2. Reich, P.B.; Tjoelker, M.G.; Walters, M.B.; Vanderklein, D.W.; Buschena, C. Close association of RGR, leaf and root morphology, seed mass and shade tolerance in seedlings of nine boreal tree species in high and low light. Funct. Ecol. 1998, 12, 327-338. [CrossRef]

3. Niklas, K.J. Plant Allometry: The Scaling of Form and Process; The University of Chicago Press: Chicago, IL, USA, 1994.

4. Cheng, D.L.; Niklas, K.J. Above-and below-ground biomass relationships across 1534 forested communities. Ann. Bot. 2007, 99, 95-102. [CrossRef] [PubMed]

5. Niklas, K.J.; Cobb, E.D.; Niinemets, Ü.; Reich, P.B.; Sellin, A.; Shipley, B.; Wright, I.J. “Diminishing returns” in the scaling of functional leaf traits across and within species groups. Proc. Natl. Acad. Sci. USA 2007, 104, 8891-8896. [CrossRef] [PubMed]

6. Shipley, B. Structured interspecific determinants of specific leaf area in 34 species of herbaceous angiosperms. Funct. Ecol. 1995, 9, 312-319. [CrossRef]

7. Milla, R.; Reich, P.B.; Niinemets, Ü.; Castro-Díez, P. Environmental and developmental controls on specific leaf area are little modified by leaf allometry. Funct. Ecol. 2010, 22, 565-576. [CrossRef]

8. Niinemets, Ü.; Kull, O. Biomass investment in leaf lamina versus lamina support in relation to growth irradiance and leaf size in temperate deciduous trees. Tree Physiol. 1999, 19, 349-358. [CrossRef] 
9. Niinemets, Ü.; Portsmuth, A.; Tena, D.; Tobias, M.; Matesanz, S.; Valladares, F. Do we underestimate the importance of leaf size in plant economics? Disproportional scaling of support costs within the spectrum of leaf physiognomy. Ann. Bot. 2007, 100, 283-303. [CrossRef]

10. Pickup, M.; Westoby, M.; Basden, A. Dry mass costs of deploying leaf area in relation to leaf size. Funct. Ecol. 2005, 19, 88-97. [CrossRef]

11. Sun, J.; Fan, R.; Niklas, K.J.; Zhong, Q.; Yang, F.; Li, M.; Chen, X.; Sun, M.; Cheng, D. “Diminishing returns” in the scaling of leaf area vs. dry mass in Wuyi Mountain bamboos, Southeast China. Am. J. Bot. 2017, 104, 993-998. [CrossRef]

12. Niklas, K.J.; Enquist, B.J. Invariant scaling relationships for interspecific plant biomass production rates and body size. Proc. Natl. Acad. Sci. USA 2001, 98, 2922-2927. [CrossRef] [PubMed]

13. Milla, R.; Reich, P.B. The scaling of leaf area and mass: the cost of light in terception increases with leaf size. Proceedings of the Royal Society B: Biological Sciences 2007, 274, 2109-2114. [CrossRef] [PubMed]

14. Pan, S.; Liu, C.; Zhang, W.; Xu, S.; Wang, N.; Li, Y.; Gao, J.; Wang, Y.; Wang, G. The scaling relationships between leaf mass and leaf area of vascular plant species change with elevation. PLoS ONE 2013, 8, e76872. [CrossRef] [PubMed]

15. Liu, G.F.; Freschet, G.T.; Pan, X.; Cornelissen, J.; Li, Y.; Dong, M. Coordinated variation in leaf and root traits across multiple spatial scales in Chinese semi-arid and arid ecosystems. New Phytologist 2010, 188, 543-553. [CrossRef]

16. Li, M.; Zheng, Y.; Fan, R.R.; Zhong, Q.L.; Cheng, D.L. Scaling relationships of twig biomass allocation in Pinus hwangshanensis along an altitudinal gradient. PLoS ONE 2017, 12, e0178344. [CrossRef]

17. Sun, J.; Wang, M.T.; Lyu, M.; Niklas, K.J.; Zhong, Q.L.; Li, M.; Cheng, D.L. Stem Diameter (and Not Length)Limits Twig Leaf Biomass. Frontiers in Plant Science 2019, 10, 185. [CrossRef]

18. Warton, D.I.; Duursma, R.A.; Falster, D.S.; Taskinen, S. Smatr 3-an Rpackage for estimation and inference about allometric lines. Methods Ecol. Evol. 2012, 3, 257-259. [CrossRef]

19. Niklas, K.J.; Cobb, E.D. Evidence for "diminishing returns" from the scaling of stem diameter and specific leaf area. Am. J. Bot. 2008, 95, 549-557. [CrossRef]

20. Givnish, T.J.; McDiarmid, R.W.; Buck, W.R. Fire adaptation in Neblinariaceliae (Theaceae), a high-elevation rosette shrub endemic to a wet equatorial tepui. Oecologia 1986, 70, 481-485. [CrossRef]

21. Niinemets, Ü. Global-scale climatic controls of leaf dry mass per area, density, and thickness in trees and shrubs. Ecology 2001, 82, 453-469. [CrossRef]

22. Ogawa, K.; Adu-Bredu, S.; Yokota, T.; Hagihara, A. Leaf biomass changes with stand development in Hinoki cypress (Chamaecyparis obtusa [Sieb. \& Zucc.] Endl.). Plant Ecol. 2010, 211, 79-88. [CrossRef]

23. Drake, J.E.; Davis, S.C.; Raetz, L.M.; Delucia, E.H. Mechanisms of age-related changes in forest production: The influence of physiological and successional changes. Glob. Chang. Biol. 2011, 17, 1522-1535. [CrossRef]

24. Niklas, K.J. Plant Biomechanics: An Engineering Approach to Plant Form and Function; The University of Chicago Press: Chicago, IL, USA, 1992.

25. Niinemets, Ü.; Portsmuth, A.; Tobias, M. Leaf size modifies support biomass distribution among stems, petioles and mid-ribs in temperate plants. New Phytol. 2006, 171, 91-104. [CrossRef] [PubMed]

26. Li, G.Y.; Yang, D.M.; Sun, S.C. Allometric relationships between lamina area, lamina mass and petiole mass of 93 temperate woody species vary with leaf habit, leaf form and altitude. Funct. Ecol. 2008, 22, 557-564. [CrossRef]

27. Niklas, K.J. The evolution of leaf form and function. In Leaf Development and Canopy Growth; Marshall, B., Roberts, J.A., Eds.; Scheffield Academic Press: Scheffield, UK, 2000.

28. Niklas, K.J. A mechanical perspective on foliage leaf form and function. New Phytol. 1999, 143, $19-31$. [CrossRef]

29. Zhu, J.D.; Meng, T.T.; Ni, J.; Su, H.X.; Xie, Z.Q.; Zhang, S.R.; Zheng, Y.R.; Xiao, C.W. Within-leaf allometric relationships of mature forests in different bioclimatic zones vary with plant functional types. Chin. J. Plant Ecol. 2011, 35, 687-698. [CrossRef]

30. Sun, S.C.; Jin, D.M.; Shi, P.L. The leaf size-twig size spectrum of temperate woody species along an altitudinal gradient: An invariant allometric scaling relationship. Ann. Bot. 2006, 97, 97-107. [CrossRef] 
31. Xiang, S.; Wu, N.; Sun, S. Within-twig biomass allocation in subtropical evergreen broad-leaved species along an altitudinal gradient: Allometric scaling analysis. Trees 2009, 23, 637-647. [CrossRef]

32. Woodward, F.I.; Lomas, M.R.; Kelly, C.K. Global climate and the distribution of plant biomes. Philos. Trans. R. Soc. Lond. B Biol. Sci. 2004, 359, 1465-1476. [CrossRef]

33. Yang, Y.; He, X.; Xu, X.; Yang, D. Scaling relationships among twig components are affected by sex in the dioecious tree Populus cathayana. Trees 2015, 29, 737-746. [CrossRef]

(C) 2019 by the authors. Licensee MDPI, Basel, Switzerland. This article is an open access article distributed under the terms and conditions of the Creative Commons Attribution (CC BY) license (http://creativecommons.org/licenses/by/4.0/). 